\title{
Bim Execution Plan in Czech Republic
}

\author{
Otmar Hrdina*1, Petr Matějka² \\ ${ }^{1}$ Faculty of Civil Engineering, Czech Technical University in Prague, Thakurova 7/2077 \\ 16629 Prague 6 - Dejvice, Czech Republic, otmarhrdina@volny.cz, +420-736-277-206 \\ ${ }^{2}$ Faculty of Civil Engineering, Czech Technical University in Prague, Thakurova 7/2077 \\ 16629 Prague 6 - Dejvice, Czech Republic
}

\begin{abstract}
As BIM (Building Information Modeling) has been used and discussed in construction projects in the Czech Republic, the need of BEP (BIM Execution Plan) templates has become a priority. This paper is focused on the survey about BIM and BEP knowledge among the Czech public and construction experts interested in BIM. This paper explains BIM and the documentation created in BIM projects and describes the main BEP chapters and benefits for BIM project.
\end{abstract}

\section{Keywords}

Building Information Modeling (BIM), BIM Execution Plan (BEP), Czech BEP template (CzBEP), Project Information Model (PIM), Asset Information Model (AIM), Employers Information Requirements (EIR), Common Data Environment (CDE), Standards, Process Maps, Information Exchanges

\section{JEL Classification}

L24 Contracting Out; Joint Ventures; Technology Licensing

DOI: https://doi.org/10.14311/bit.2016.02.03

Editorial information: journal Business \& IT, ISSN 2570-7434, CreativeCommons license (c) () published by CTU in Prague, 2016, http://bit.fsv.cvut.cz/ 


\section{Introduction}

BIM (Building Information Modeling) is drawing the attention of the public and building professionals in the Czech Republic. They have seen the benefits described in construction projects abroad and they want use BIM methodology too. BIM methodology is quite new in the Czech Republic, and it is a new theory which must be understood so it can be implemented correctly. BIM is also a tool for the next industry revolution (4.0) which can be used with the help of information technology and electronic devices which people currently use.

\section{Methodology}

An online survey was conducted for the purpose of collecting information about the knowledge and understanding of BIM among Czech construction professionals. It should show how people are interested in BIM and if they use BEP (BIM Execution Plan). The online questionnaire was shared amongst some construction companies and enterprises to gather results about BIM and BEP knowledge.

Sources from outside the Czech Republic were used to learn about BIM and BEP. States like USA, Great Britain, Finland, Holland and also Singapore and Hong Kong have sophisticated and practiced documents and systems used in BIM. These sources were used to learn about the theoretical and practical parts of BIM and BEP.

\section{Results}

The paper consists of a questionnaire description and its results; then it describes the BIM document cycle which is used in Great Britain and at last it describes BEP.

\section{The Questionnaire}

Questions asked in the survey were as following:

- First question: Do you work with BIM?

- Second question: Have you ever taken part in any training about BIM?

- Third question: Do you use BEP or any other document like this?

- Fourth question: Would a BEP be template useful for you?

33 responses were collected from construction organizations, engineers, architects and other employers working in civil engineering. The results of the survey are as following:

Respondents answered the first question $12.5 \%$ YES. It means they are working with BIM. $62.5 \%$ answered NO, so they are not working with BIM or they are not interested in BIM. And there was also an option to answer PARTLY, for those who are not working fully in BIM, but are using some of its tools or parts. Results of the first question show, that BIM is not yet expanded in construction projects. But there is a sign that BIM is rising in the Czech construction scene and construction experts are interested in BIM.

The results of the second question are $54.8 \%$ for YES and $45.2 \%$ for NO. It shows, that construction experts are interested in enhancing their knowledge about BIM and also with its associated problems. They are seeking training and information about BIM.

The third question aimed on using BEP has the following results. YES has answered $21.2 \%$ of the respondents and NO $78.8 \%$. It signifies that BEP is not widely expanded and the BEP template for the Czech Republic should be established for common use in construction projects. 
The fourth question $62.3 \%$ answered YES and $38.7 \%$ NO. It shows quite a large interest about the BEP template but on the other hand some enterprises which create their own templates are not interested. Even so, there must be a common standardized template created and supported with both legal and government agreements. Once that is completed, then the template can be used in public and private construction projects like a common document that will contain all necessary agreements and legal terms.

Table 1: Results of the survey (author)

\begin{tabular}{|l|l|l|l|}
\hline Question & YES & NO & PARTLY \\
\hline Do you work with BIM? & $12,5 \%$ & $62,5 \%$ & $25 \%$ \\
\hline $\begin{array}{l}\text { Have you ever visited any } \\
\text { training about BIM? }\end{array}$ & $54,8 \%$ & $45,2 \%$ & - \\
\hline $\begin{array}{l}\text { Do you use BEP or any other } \\
\text { document like this? }\end{array}$ & $21,2 \%$ & $78,8 \%$ & - \\
\hline $\begin{array}{l}\text { Will be BEP template useful } \\
\text { for you? }\end{array}$ & $61,3 \%$ & $38,7 \%$ & - \\
\hline
\end{tabular}

Interest of construction experts and corporations is apparent in dealing with BIM and as well with BEP and its template. Construction experts seek BIM solutions for their companies and work in BIM, as well as information about BEP and other parts of BIM documentation. BIM in the Czech Republic is at its beginning stages but the initiation has already started. BEP template [1] has already been created, CzBEP, and it is the first starter document for future use and developing BEP for the Czech Republic.

\section{Cycle of information and documents}

Implementing BIM and its methodology depends on every single state. For the purposes of this paper, the British approach of the methodology was selected. In Great Britain, PAS 1192 (Publicly Available Specification) is used which consists of five linked parts. In the following text the second part labeled PAS 1192: 2 will be explained. 


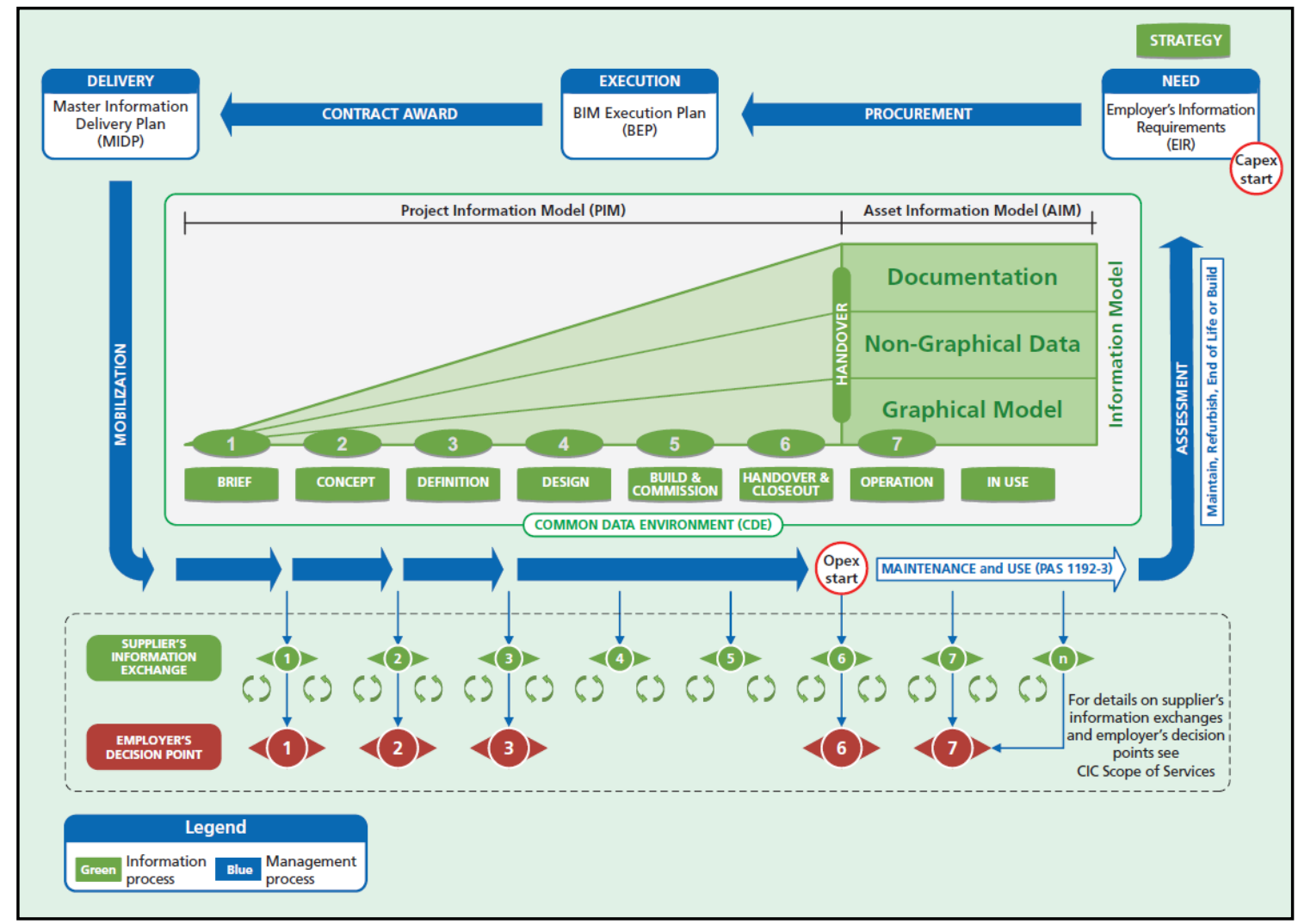

Figure 1: The information delivery cycle [2]

Every project is initiated with EIR (Employer Information Requirements) at Capex which represents the first investment to physical assets. EIR defines the information that will be required by the employer from the internal team, from suppliers of the development of the project and for the operation of the completed built asset. Major parts from the employer's information requirements are included in the procurement documents for the appointment of each supplier, advisor, consultant and contractor. Documents should clearly articulate the information requirements for each supplier and describe the expected information deliverables in terms of documents, model files and structured information. It should also define how and when information should be exchanged in the project lifecycle according with project phases.

About BEP documents. In the procurement phase a pre-contract BEP is created. It is a response to the EIR described above. The pre-contract BEP includes a Project Implementation Plan (PIP) which describes the suppliers IT and human resources capability to deliver the EIR. It may also describe goals for information modeling, project milestones and delivery strategy.

There is also post-contract award BEP created after the contract is awarded to the selected contractor or contractors. It describes in detail and sets out how the information required in the EIR will be provided. Major chapters of post BEP are about management, planning, documentation, standards and IT solutions.

The management chapter mainly describes roles, responsibilities and authorities, project milestones, deliverable strategy, survey strategy and so on.

Planning and documentation includes a revised PIP confirming the capability of the supply chain, agreed processes for collaboration and modeling and a matrix of responsibilities.

It also includes a Task Information Delivery Plan (TIDP) which sets out the responsibility for the delivery of each supplier's information and a Master Information Delivery Plan (MIDP) that sets out when project information is to be prepared, by whom and using which protocols and procedures. 
The standard method and procedure sets out the volume strategy, origin and orientation, file naming convention, layer naming convention, construction tolerances, drawing sheet templates, annotation, dimensions, abbreviations and symbols, attribute data,

The IT solution sets out software versions, exchange formats, process and data management systems. This system is CDE, which stands for common data environment (CDE). It is the single source of information used to collect and manage documentation both graphical model and non-graphical data for the whole project team. Creating this single source of information facilitates collaboration between project teams and other members and helps to avoid duplication of work and misunderstandings.

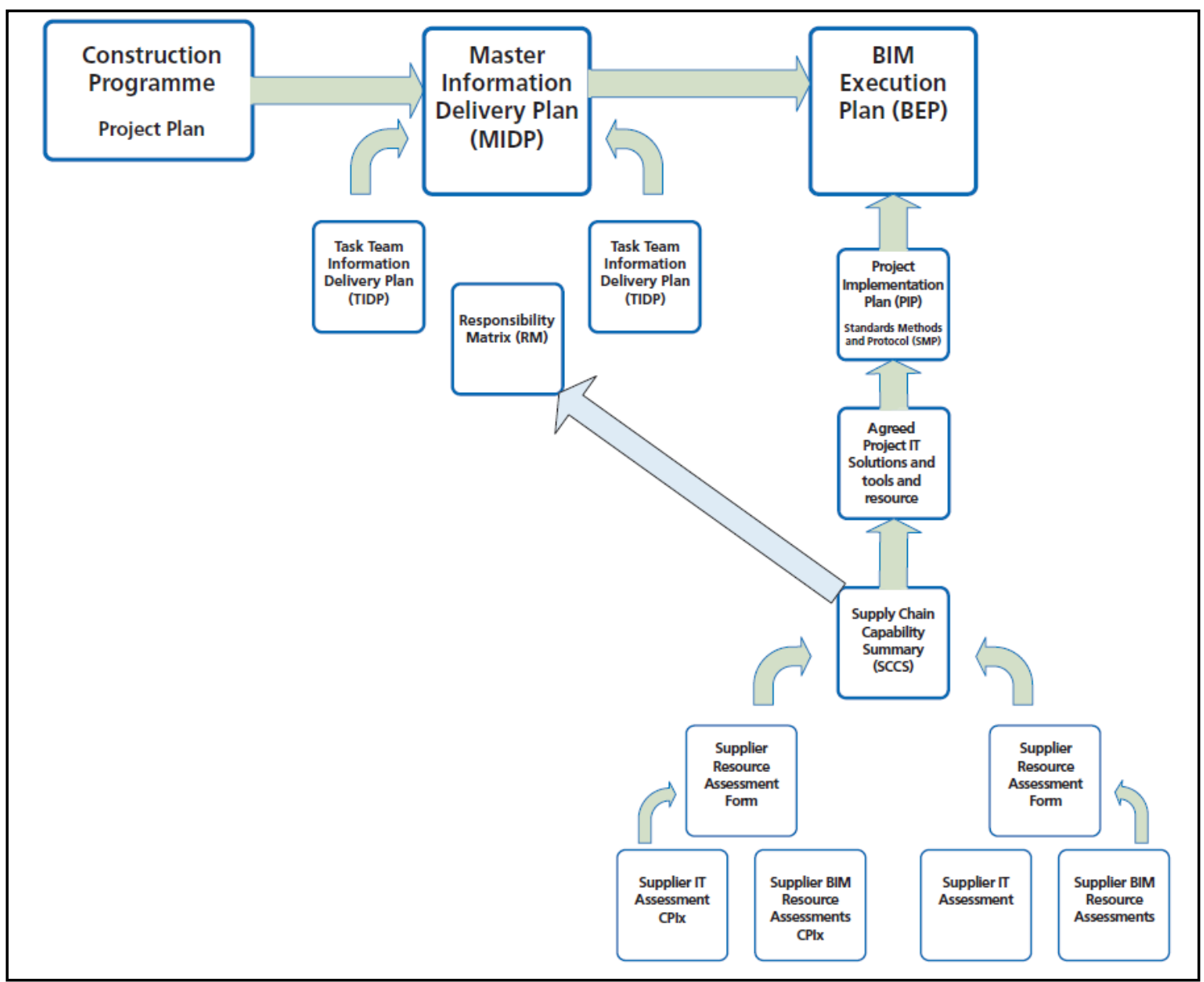

Figure 2: Relationship between documents used for information management [2]

In the procurement phase, assessment forms are also created. There are three forms in which the suppliers describe their maturity in information technology, resources and in BIM as well.

A supplier IT Assessment Form provides a meaningful method of assessing supply chain information exchange capability and supply chain IT maturity. It describes information exchanges, used software and systems.

A BIM Assessment Form enables a design consultancy firm or supply chain company to demonstrate competence in and understanding of BIM. It is ensured by a set of prepared questions about BIM. There a supplier can also highlight their previous experiences in BIM projects.

In the Supplier Assessment Form documents about human resources are provided, how is supplier experienced and qualified in BIM, how many years of experience and employees he has and so on. 


\section{The BEP}

BEP represents final document which unite all project parties. It detail previous documents and aim for BIM project details. Finished BEP should define appropriate BIM uses e.g. design authoring, cost estimating, design reviews etc. Once the plan is finished the project team can follow it for monitoring its progress and raise benefits from implementation of BIM.

Main points of BEP creation according to [3] are:

- Identify high value BIM uses during project planning, design, construction and operational phases

- Design the BIM execution process by creating process maps

- Define the BIM deliverables in the form of information exchanges

- Develop the infrastructure in the form of contracts, communication procedures, technology and quality control to support the implementation

The goal of creating this structured procedure is to encourage planning and direct communication within the project team during the early phases of the project. A leading team planning process should include members from all organizations who have a significant role in the project. So the participants are employer, owner, contractor, subcontractors and facility manager.

Since there is no best method or universal method of BIM implementation usable for every project, competent team must design effective, tailor-made strategy for the particular project, with an understanding of its objectives, characteristics, and ability of the members of each team and the EIR.

\section{Reasons of BEP creation}

The main reason for the creation of BEP is the effective integration of BIM in the project. For the team it is necessary to develop a detailed implementation plan and describe the main features of the project and overall vision together with the implementation details. This implementation plan is monitored by project team which controls it throughout the project lifecycle.

The BEP project teams define the scope of BIM implementation in the project, identify procedural practices for BIM processes that define the information exchange between the participants and the required infrastructure to support its optimal use.

By developing a BIM Plan, the project and project team members can achieve the following value:

- All parties will clearly understand and communicate the strategic goals for implementing BIM on the project

- Organizations will understand their roles and responsibilities in the implementation

- The team will be able to design an execution process which is well suited for each team member's business practices and typical organizational workflows

- The plan will outline additional resources, training, or other competencies necessary to successfully implement BIM for the intended uses

- The plan will provide a benchmark for describing the process to future participants who join the project

- The purchasing divisions will be able to define contract language to ensure that all project participants fulfill their obligations

- The baseline plan will provide a goal for measuring progress throughout the project.

- Teams avoid risks connected with BIM implementation and inexperienced cooperation teams.

Project will always benefit from a higher level of planning and by reducing the unknown and missing information during the implementation process. This will reduce overall risk for all groups involved in the project. 
Neglecting the creation of BEP or similar document in the form of a standard for the model and the list of required BIM outputs runs the project team to various risks. These may be for example failure to meet customer requirements, creating an incomplete model outcome, financial losses when implementing BIM tools, overrun of estimated expenditures, unexploited potential of BIM methodologies and tools.

\section{Conclusion and discussion}

Conclusion of the questionnaire is the fact that BIM is in the Czech Republic on its rise. It is getting into the consciousness of construction professionals and companies. They count with BIM implementation and maybe they see BIM as a new method of construction. According to BEP there can be seen interest about it. Construction companies are creating their own BEPs but there is need to create common template which will be used in contracting and will be legislatively supported.

The questionnaire brought us an affirmative answer to the question if the BEP template will found its use in Czech Republic.

Overview about BIM methodology and information cycle describes documents used in BIM. For the purpose of the research special BEP template named CZBEP was created. It includes the best practices used by abroad companies on their projects. BEP is crucial for interoperability specification in construction industry [9], along with other relevant protocols [10].

\section{Acknowledgement}

This work was supported by the Grant Agency of the Czech Technical University in Prague, grant SGS15/132/OHK1/2T/11: Vyhodnocování efektivity výstavbových projektů při použití metodiky BIM

\section{References}

[1] HRDINA, O. Role BEP ve výstavbových projektech a specifikace obsahu: BEP in construction projects. Praha. Diplomová práce: Diploma thesis. České vysoké učení technické v Praze: CTU in Prague, Katedra ekonomiky a řízení ve stavebnictví.

[2] UK. Specification for information management for the capital/delivery phase of construction projects ..., Collaborative production of information. The British Standards Institution, 2013. ISBN 978-0-580-826665 .

[3] COMPUTER INTEGRATED CONSTRUCTION RESEARCH PROGRAM. BIM Project Execution Planning Guide. 2.1. Pennsylvania: The Pennsylvania State University, 2011.

[4] UK, Post-Contract-Award Building Information Modelling (BIM) Execution Plan (BEP). Construction Project Information Committee, 2013.

[5] UK, Pre-Construction Building Information Modelling (BIM) Execution Plan (BEP). Construction Project Information Committee, 2013.

[6] HOLZER, D. The BIM Manager's Handbook. John Wiley \& Sons Inc, 2016. ISBN 978-1-118-98242-6.

[7] UK. AEC (UK) BIM Protocol v2.0, Implementing UK BIM Standards fot the Architectural, Engineering and Construction industry. BIM UK Commitee, 2012.

[8] LIMITED, D. B. Design Building Wiki [online]. version 26.6.2016. Available from: https://www.designingbuildings.co.uk/wiki/Home

[9] Arayici, Y., Fernando, T., Munoz, V., \& Bassanino, M. (2018). Interoperability specification development for integrated BIM use in performance based design. Automation in Construction, 85, 167-181. https://doi.org/10.1016/j.autcon.2017.10.018

[10] Sacks, R., Gurevich, U., \& Shrestha, P. (2016). A review of building information modeling protocols, guides and standards for large construction clients. Journal of Information Technology in Construction, 21, 479-503. 